\title{
Proceeding
}

10th INSHS International Christmas Sport Scientific Conference, 4-5 December 2015. International Network of Sport and Health

Science. Szombathely, Hungary

\section{Muscle activation of a sportsman and an untrained man}

\author{
PAVEL KORVAS ${ }^{1}$, MARKÉTA KOŤOVÁ 2 , PAVLA HORÁKOVÁ 2 \\ ${ }^{1}$ Centre of Sport Activities, Brno University of Technology, Brno, Czech Republic \\ ${ }^{2}$ Department of Biomedical Engineering, Brno University of Technology, Brno, Czech Republic
}

\begin{abstract}
The research was focused to analyse the muscle activation using SEMG during repeated physical activity. The purpose of this study was to find out differences between a sportsman and an untrained man in the timing of muscle activation during increasing load. Two men took part in the research. The untrained man (MN) 20 years old, $180 \mathrm{~cm}, 74 \mathrm{~kg}$, sportsman (MS) 22 years old, $177 \mathrm{~cm}, 87 \mathrm{~kg}$. Participants performed repeated flexion and extension in the elbow joint. Muscle activation has been tested using sEMG on the selected muscles: biceps brachii (BB), brachioradialis (B), trapezius $p$. descendez (TD), deltoideus $p$. acromialis (DA). Both participants performed test for 5,8 and $12 \mathrm{~kg}$ load. Number of repetition was 10. In flexion, the time of muscle activations were the same or very similar for BB for both participants and longer in MN for B and DA, for TD were longer in MS for all loads. Differences were caused firstly by a different finishing time. In extension DA and B in MN, partly also TD were activated for a longer time. The time for activation of BB was mostly the same. Differences were caused mainly by the later start of the activation in MS. Also tendencies in prolonging and shortening the time of activation in relation to increasing load in both participants demonstrated different characteristics. Significantly longer time of muscle activation of MN has been proved only for B and DA for both kinds of movements. Differences between participants in the total time of activation at absolutely same load were expected especially because of the better movement efficiency, adaptation to the power load and movement technique in MS. Key words: EMG, FLEXION, EXTENSION, TIMING.
\end{abstract}

Corresponding author. Centre of Sport Activities, Brno University of Technology, Technická 2896/2, 61669 Brno, Czech Republic

E-mail: korvas@cesa.vutbr.cz

10th INSHS International Christmas Sport Scientific Conference, 4-5 December 2015. International Network of Sport and Health Science. Szombathely, Hungary.

JOURNAL OF HUMAN SPORT \& EXERCISE ISSN 1988-5202

(c) Faculty of Education. University of Alicante

doi:10.14198/jhse.2016.11.Proc1.01 


\section{INTRODUCTION}

Muscle activity, neuromuscular activity, stimuli of the muscle activity represent complex issues which are studied by kinanthropology from different points of view. An important area which deals with emergence of movement activity, its correct execution as well as neuromuscular activity is kinesiology which often uses methods of EMG (electromyography). With the use of EMG it is possible to monitor manifestations of the muscle electric activity (Rodová et al., 2001), which helps to study physiological processes related to the movement activity. This method quantifies electric manifestations of neuromuscular activity - amplitude, frequency or timing (e.g. Bilodeau et al. 2003; Konrad, 2005). Kinesiological orientation of EMG can be described as the study of neuromuscular activation of muscles during observation of functional movement activity and regime of muscles during their activity (Konrad, 2005). Variability of the EMG record of muscle activity and methods of assessment are used for various purposes in ergonomics, biomechanics, kinematics, sports training, rehabilitation or investigation into the kinesiology behaviour etc. (Rainoldi et al., 2004; Konrad, 2005).

EMG is used in practice with certain restrictions even for the general estimation of the muscle power during both static and dynamic muscle activity (Madeleine et al., 2000). Activation interval is useful for evaluation of muscle coordination and effects of the treatment (Benedetti, 2001; Sutherland, 2001), myoelectric fatigue (Merletti et al., 1990; De Luca, 1997), neuromuscular adaptation influenced by age (Merletti and Bonalo, 2008) or muscle inactivity (Edgerton and Roy, 1994; Berg et al., 1997). Studies usually concentrate on basic EMG characteristics in isometric or isotonic muscle activity and on evaluation of the time series of stimuli timing (Turpin, 2011). Majority of research studies deals with voluntary isometric contraction for which it is easier to carry out a stable technique of the examined muscle during measurement (Yamaguchi et al., 1997; Nizam et al., 2012). Minor part of the studies deals with EMG responses and their changes during repeated isotonic cyclic activity of various muscles. Dynamic contraction brings higher demands on methodology and accuracy during recording of the measurement itself (Kellis and Baltzopoulos, 1998, Turpin, 2011). Studies concentrating on muscle coordination deal with muscle activity of individual muscles or with EMG pattern of their activities. From this EMG profile, information about time activation during the course of the movement cycle and shape or level of muscle activity is used (Solomonow et al., 1990; Hug, 2011). Contemporary technology is able to record EMG activity of more muscles and sum it into the summary activation of muscle synergies in complex movement activity (Ting \& McKay, 2007). Muscle synergies represent a complex time and space organisation of motor performance and it is possible to use them for evaluation of motor strategy of the individual (Hug, 2011). Number of studies dealt with the influence of movement intervention or various types of resistance on the stimuli of the muscle activity in various muscle groups e.g. Hughes and McBride (2005), Bosch et al., (2011). The issue of EMG during muscle activity of upper extremities and shoulder girdle was dealt with in number of studies both during static and dynamic load (Sergio \& Ostry, 1995; Flanders, 1991; Jongen et al., 1989) with various results.

Both for the research and practice, invasive and non-invasive techniques are used for monitoring and recording of EMG signal. During active movement activity, it is more convenient to use surface EMG (sEMG) which is confirmed by many studies, even if the invasive EMG using needles is more accurate. (De Luca, 1997; Merletti and Bonalo, 2008).

To find more about the stimuli of muscle activity, a pilot study has been carried out which aim has been to find out possible existence of differences in the time lines of the stimuli in the movement cycle between differently physically active individuals. Firstly the study dealt with the strategy of activation of selected muscle groups which are important for execution of the given movement activity task. 
The aim of the study was evaluation of the time series of stimuli of the muscle activity in selected muscles which are involved in flexion and extension in the elbow during the movement cycle with the same load.

We supposed that the time organisation of the recruitment of selected muscles during movement cycle will be different for the sportsman and for the untrained man and that the differences will be getting bigger in relation to the increasing load.

\section{MATERIAL AND METHODS}

This research survey is based on the intention to analyse stimuli of the muscle activity using sEMG in repeated simple dynamic movement activity. The pilot comparative study was looking for the differences in the timing of the muscle activation between two extremes, a well-trained sportsman and an untrained individual, during increasing load.

\section{Participants}

Untrained man (MN), 20 years old, height $180 \mathrm{~cm}$, weight $74 \mathrm{~kg}$, movement activity once a week. Well trained sportsman (MS), 22 years old, height $177 \mathrm{~cm}$, weight $87 \mathrm{~kg}$, training unit 4 - 5 times a week.

\section{Measures}

Non-invasive method of surface electromyography (sEMG) with synchronised video recording was used for the kinesiology analysis of the selected movement structure (De Luca, 1997). Taking the electric activity of the muscles was performed by a 16-channel telemetric EMG with the Wave Plus system (Cometa, Italy). Device is provided with 16-bit resolution and sampling frequency $2,000 \mathrm{~Hz}$. Bio potentials were taken via solid surface gel electrodes EK-S45PSGB1 with Ag/AgCl sensor, diameter $10 \mathrm{~mm}$ (SORIMEX, Poland). Electromyographic signals were saved in the digital form and processed after accomplishment of the measurement. Program MATLAB version R2013a was used for processing the signals and statistics. Each channel of the EMG signal was first transformed into absolute value and filtrated in a way that the envelope of each signal was obtained. Detection of the stimuli of the muscle activity was performed on the obtained envelopes into individual movement cycles automatically using data from the envelopes. Course of the movement was segmented into individual movement cycles automatically using data from the triaxial accelerometer with 10-bit resolution which forms part of the electrode part of the EMG sensing device. Accelerometer placed on the brachioradialis $\mathrm{m}$. was used for determination of both beginning and termination of the movement cycle.

In every movement cycle, local extremes were found and average from 10 maxima was counted on the envelope of the signal. Sections of the envelope overreaching $40 \%$ of the local maximum were marked as the level influencing muscle activity (Špulák, 2012). Time series of muscle activation in every movement of the cycle were evaluated. Detection was performed in every movement of the cycle and it was possible to create an average pattern of time series and compare repeatability of the activities of individual muscles, and possible differences in the order of muscle activations as well as deactivations in the movement cycles for individual amount of load. Electrodes were placed on the selected muscles according to the methodology by Konrad (2005).

\section{Procedures}

A simple movement performed in the sagittal plane was set to decrease most differences in abilities between the sportsman and the untrained research participant. Active flexion and extension were performed in the elbow joint in one degree of freedom with the support of the arm from armpit to the elbow on the pad of the fitness machine. Machine was adapted to the height of the tested person as well as the length of his arms. 
Each research participant was carrying out flexion and extension in the elbow on his own speed and rhythm without pauses at the end of the movement activity cycle. Both research participants carried out repeated flexion and extension in the elbow at the load of 5,8 and $12 \mathrm{~kg}$. Each individual performed a warm up exercise before the beginning of the research and was instructed in the correct execution of the tested movement. Participants of the research started with the lowest load and performed 10 repeated activities, followed by a 3-minute pause, and then performed activity with higher load a continued up to the highest tested load. Data from the $2^{\text {nd }}$ to $9^{\text {th }}$ movement cycle was evaluated. According to Hug (2011), sufficient number of evaluated sections for obtaining a representative sample is 6 to 10 periods.

Muscles which are essential for realisation of the given movement task were chosen. Selected muscles monitored using sEMG were: brachial biceps muscle, descending part of a trapezius muscle, the acromial part of the deltoideus muscle and brachioradialis muscle. Selected muscles were divided into two groups from the biomechanic point of view: into primary working muscles in flexion and extension (brachial biceps $\mathrm{m}$. and brachioradialis $\mathrm{m}$.) and secondary muscles (descending part of a trapezius $\mathrm{m}$. and the acromial part of the deltoid $\mathrm{m}$.) which do not play the main role during flexion and extension but stabilise the shoulder girdle area which is being loaded (they are auxiliary muscles).

Following parameters were chosen for the study of the strategy of muscle activation: duration of the movement cycle, relative period of the stimuli of individual muscles in the frame of the movement cycle, the beginning and termination of the muscle activation in the movement cycle.

The design of the study was approved by the local Ethical Committee and was conducted in accordance with the Declaration of Helsinki.

\section{Analysis}

Basic descriptive statistics was used for obtaining of average values of time series of the stimuli from the individual repeated cycles. Evaluation was factual. The differences of the beginning, termination or the total time of activation up to $5 \%$ was considered as congruent.

\section{RESULTS}

Time series of the stimuli of muscle activity in the movement cycle of the given task during load at 5, 8 and $12 \mathrm{~kg}$ of every research participant were evaluated. 8 out of 10 ( $2-9$ cycle) performed cycles were averaged for the evaluation. Average time of the movement cycles at individual levels of load for both research participants can be seen in table 1.

Table 1. Average duration of movement cycles of both research participants during individual types of load (sec)

\begin{tabular}{cccccccc}
\hline & \multicolumn{3}{c}{ Flexion } & \multicolumn{3}{c}{ Extension } \\
\hline Load & & $5 \mathrm{~kg}$ & $8 \mathrm{~kg}$ & $12 \mathrm{~kg}$ & $5 \mathrm{~kg}$ & $8 \mathrm{~kg}$ & $12 \mathrm{~kg}$ \\
\hline \multirow{2}{*}{$\mathrm{MN}$} & $\mathrm{M}$ & 1,217 & 1,406 & 1,515 & 1,393 & 1,597 & 1,567 \\
& $\mathrm{SD}$ & 0,097 & 0,102 & 0,105 & 0,109 & 0,098 & 0,121 \\
\hline \multirow{2}{*}{$\mathrm{MS}$} & $\mathrm{M}$ & 0,687 & 0,692 & 0,721 & 0,711 & 0,703 & 0,73 \\
& $\mathrm{SD}$ & 0,087 & 0,104 & 0,095 & 0,094 & 0,089 & 0,111 \\
\hline
\end{tabular}


Legend: MN - untrained man, MS - sportsman

In both research participants, performance of flexion was always faster than extension at all levels of load. In MS, time differences between flexion and extension were minimal, on average $2.5 \%$ but in MN these average differences reached $10.5 \%$. MS performed both flexion and extension significantly faster than MN. In flexion, MS reached average time of $51.1 \%$ of the time of MN. In extension this average time was at $47.2 \%$ of the time of MN.

\section{Strategy of muscle activity activation for selected muscles}

Timing values (time series of the stimuli) of the activation of muscle activity during flexion and extension in elbow joint are shown in tables 2, 3 .

Table 2. Average relative time of activation of muscle activity (\% of movement cycle) in both arms within movement cycle at observed load during flexion and extension

\begin{tabular}{cccccc}
\hline \multicolumn{5}{c}{} & \multicolumn{4}{c}{ Flexion / Extension } \\
\hline Proband & Load $(\mathrm{kg})$ & Trapezius & Deltoideus & Brachioradialis. & Biceps \\
\hline MN & 5 & $59 / 78$ & $79 / 76$ & $85 / 79$ & $71 / 55$ \\
MN & 8 & $71 / 75$ & $84 / 86$ & $87 / 78$ & $77 / 77$ \\
MN & 12 & $71 / 84$ & $77 / 94$ & $92 / 97$ & $80 / 79$ \\
\hline MS & 5 & $85 / 70$ & $73 / 57$ & $70 / 55$ & $67 / 53$ \\
MS & 8 & $80 / 73$ & $77 / 68$ & $79 / 64$ & $80 / 61$ \\
MS & 12 & $80 / 76$ & $89 / 57$ & $78 / 81$ & $87 / 82$ \\
\hline
\end{tabular}

Legend: $\mathrm{T}$ - trapezius m., $\mathrm{D}$ - deltoideus $\mathrm{m}$., $\mathrm{B}$ - brachioradialis $\mathrm{m}$., $\mathrm{Bi}$ - biceps brachii $\mathrm{m}$.

Table 3. The beginning and termination of muscle activation (\% of movement cycle) in both research participants

\begin{tabular}{ccccccccccc}
\hline & \multicolumn{1}{c}{ Flexion } & \multicolumn{1}{c}{ Extension } \\
\hline Proband & $\begin{array}{c}\text { Load } \\
(\mathrm{kg})\end{array}$ & $\begin{array}{c}\text { Activation } \\
(\% \text { of MC) }\end{array}$ & $\mathrm{T}$ & $\mathrm{D}$ & $\mathrm{B}$ & $\mathrm{Bi}$ & $\mathrm{T}$ & $\mathrm{D}$ & $\mathrm{B}$ & $\mathrm{Bi}$ \\
\hline $\mathrm{MN}$ & 5 & start & 7 & 10 & 10 & 8 & 14 & 19 & 20 & 44 \\
& & finish & 66 & 89 & 95 & 79 & 92 & 95 & 99 & 99 \\
\hline $\mathrm{MN}$ & 8 & start & 11 & 9 & 9 & 8 & 14 & 5 & 8 & 18 \\
& & finish & 82 & 93 & 96 & 85 & 89 & 91 & 86 & 96 \\
\hline $\mathrm{MN}$ & 12 & start & 17 & 15 & 6 & 6 & 9 & 3 & 3 & 21 \\
& & finish & 88 & 92 & 98 & 86 & 93 & 97 & 100 & 100 \\
\hline & & & & & & & & & & \\
\hline $\mathrm{MS}$ & 5 & start & 4 & 6 & 9 & 5 & 25 & 43 & 43 & 47 \\
& & finish & 89 & 79 & 79 & 72 & 95 & 100 & 98 & 100 \\
\hline MS & 8 & start & 6 & 7 & 10 & 8 & 26 & 32 & 36 & 39
\end{tabular}




\begin{tabular}{|c|c|c|c|c|c|c|c|c|c|c|}
\hline & & finish & 86 & 84 & 89 & 88 & 99 & 100 & 100 & 100 \\
\hline$M$ & 1 & start & 5 & 6 & 14 & 10 & 22 & 43 & 19 & 18 \\
\hline & & finish & 80 & 95 & 92 & 97 & 98 & 100 & 100 & 100 \\
\hline
\end{tabular}

Legend: $\mathrm{MC}$ - movement cycle

Average values of muscle activation of both arms were used for the description as well as for factual evaluation. Differences between research participants are given in relative values within the movement cycle of each man. Differences in the overall time, at the beginning and also termination of individual muscle activation are really specific for the individual muscles and some of them are not in accordance with assumptions.

\section{Muscle activation of both research participants at $5 \mathrm{~kg}$ load}

Description of the results of flexion

Relative time of muscle activation was significantly longer in $\mathrm{MN}$, for the deltoideus $\mathrm{m}$. by $6 \%$ and for the brachioradialis $\mathrm{m}$. by $15 \%$. In MS activation was significantly longer for the trapezius $\mathrm{m}$. by $26 \%$. Relative time of activation for the biceps $\mathrm{m}$. was without significant difference between research participants. Beginning of the activation of all muscles did not show significant differences between research participants (on average $4 \%$ ) at the very beginning of the movement cycle. Activation was finished in the majority of muscles significantly earlier in MS (except for the trapezius $\mathrm{m}$.), on average by $11 \%$ (MS between $72 \%$ $79 \%$, MN between $79 \%$ - $96 \%$ ). In the trapezius m., termination was carried out significantly later in MS by $23 \%$.

Description of the results of extension

Relative time of muscle activation was in MN significantly longer for the trapezius $\mathrm{m}$., the deltoideus $\mathrm{m}$. and the brachioradialis $\mathrm{m}$. on average by $17 \%$. For biceps $\mathrm{m}$., time of activation was identical for both research participants without significant difference. Beginning of activation was significantly earlier in $\mathrm{MN}$ for the trapezius $\mathrm{m}$., the deltoideus $\mathrm{m}$. and the brachioradialis $\mathrm{m}$. (on average by $11 \%$ ). For the biceps $\mathrm{m}$. beginning of activation did not show significant differences and it starts shortly before the middle of the movement cycle. Activation was finished in all observed muscles without significant differences between research participants (up to $5 \%$ ), at the very end of the movement cycle (92\% - $100 \%)$.

\section{Muscle activation of both research participants at $8 \mathrm{~kg}$ load}

Description of the results of flexion

Relative time of muscle activation was significantly longer in $\mathrm{MN}$, for the deltoideus $\mathrm{m}$. by $7 \%$ and for the brachioradialis $\mathrm{m}$. by $8 \%$. In MS activation was significantly longer for the trapezius $\mathrm{m}$. by $9 \%$. The biceps $\mathrm{m}$. time activation was without significant difference. Beginning of the activation of all muscles did not show significant differences (on average $3 \%$ ). Activation was finished significantly later in $\mathrm{MN}$ for the deltoideus $\mathrm{m}$. and the brachioradialis $\mathrm{m}$. (on average by $8 \%$ ). For trapezius $\mathrm{m}$. and the biceps $\mathrm{m}$., activation terminated without significant differences, later in MS by $4 \%$.

Description of the results of extension

Relative time of muscle activation was in $\mathrm{MN}$ significantly longer for the deltoideus $\mathrm{m}$. by $18 \%$, the brachioradialis $\mathrm{m}$. by $12 \%$ and the biceps $\mathrm{m}$. by $16 \%$. For the trapezius $\mathrm{m}$. time of activation did 
not show significant differences between research participants. Beginning of activation was significantly later in MS for all muscles (on average by $22 \%$ ). Activation was finished significantly later in MS for the deltoideus $\mathrm{m}$., the brachioradialis $\mathrm{m}$. and the trapezius $\mathrm{m}$. (by $11 \%$ ). The biceps $\mathrm{m}$. finished without significant difference between both men.

\section{Muscle activation of both research participants at $12 \mathrm{~kg}$ load}

Description of the results of flexion

Relative time of muscle activation was observed as significantly longer in $\mathrm{MN}$, only for the brachioradialis $\mathrm{m}$. by $14 \%$. For the remaining muscles, longer activation was observed in MS for the trapezius $\mathrm{m}$. by $9 \%$, for the deltoideus $\mathrm{m}$. by $12 \%$ and for the biceps $\mathrm{m}$. by $7 \%$. Beginning of activation was observed earlier in MN for the brachioradialis $\mathrm{m}$. by $12 \%$ and later for the deltoideus $\mathrm{m}$. by $9 \%$ and the trapezius $\mathrm{m}$. by $12 \%$. The biceps $\mathrm{m}$. did not show significant differences during the beginning of activation. Activation was terminated significantly later in $\mathrm{MN}$ for the trapezius $\mathrm{m}$. by $8 \%$ and for the brachioradialis $\mathrm{m}$. by $6 \%$. In MS later termination of activation was observed for the biceps $\mathrm{m}$. by $11 \%$. For the deltoideus $\mathrm{m}$., significant difference in termination between research participants was not observed.

Description of the results of extension

Relative time of muscle activation was in $\mathrm{MN}$ significantly longer for the trapezius $\mathrm{m}$. by $8 \%$, for the deltoideus $\mathrm{m}$. by $37 \%$ and for the brachioradialis $\mathrm{m}$. by $16 \%$. For the biceps $\mathrm{m}$. there was no significant difference observed. Activation started significantly later in MS for the trapezius $\mathrm{m}$. the deltoideus $\mathrm{m}$. and the brachioradialis $\mathrm{m}$. (on average by $23 \%$ ). The biceps $\mathrm{m}$. beginning of activation did not show any significant differences between both men. Termination of activation was carried out in both men at the end of movement cycle (between $93 \%$ - 100 \%) without significant difference between individual muscles.

\section{DISCUSSION}

Quality of movement performance is influenced both by the individual preconditions, stage of motor learning, level of fitness, skills, experience and quality of the nervous system as well as neuromuscular activity which controls the whole movement performance. This state should correspond to the stimuli of muscle activity. Neuromuscular activity has its individual characteristics in each individual. However, lifestyle, regular physical activity or training effect an adaptation to the physical load and also fatigue can contribute to muscle activity (Chimera, et.al. 2004; McCurdy, et al. 2010; Desteridis, et. al. 2012; Antonopoulos, et.al. 2014). Electromyography enables the identification of participating muscles and the sequence in which they generate movement. Quality of muscle activity depends on many factors. The main ones are the maximal number of motor units recruited during contraction, motoeneuron excitability and the type of recruited motor units (Sale et al., 1983). A specific indicator of neuromuscular activity, muscle activation timing of the selected muscles during flexion and extension of the arm in the elbow joint was monitored for the comparison in two different participants from the point of view of physical activity.

At the evaluation of absolute time of average movement cycle during flexion and extension, MS was significantly faster at all levels of load. This should be consequence of adaptation to physical training, better technique and strength preparedness of sportsman. It is logical that both research participants in most cases extended their time of movement cycle in relation to increasing load. We let to perform movement task our participants their own speed which was consequence their quality of fitness, strength preparedness, skill and technique. Important role in muscle activation strategy should play the adaptation to the load of the strength character in the sportsman as well as the fact that for the untrained man used load represented subjectively 
the scale from moderate to submaximal effort but for the sportsman just light effort. We found out timing differences between research participants and also number of very similar or consistent results. We also tried to found out tendencies in the muscle activation changes with increasing load in individual muscles. With 2 research participants, however, it was only possible to observe the indications of these tendencies. For this reason, factual evaluation was used for both analysis and comparison of differences between research participants.

The differences in muscle activation strategy during flection were not regular or the results didn't show the regular tendencies in relation to increasing load for both men. Smaller half of results of all loads were significantly different but the rest of results were quite often similar or identical. For extension were found out for most load results significant differences between both men and also tendency to regular extension of activation time within movement cycle. Generally different strategy of muscle activation between flexion and extension was found out in both research participants. Even if the movement is identical in one joint and plane and the same muscles are working, their time of muscle recruitment during movement cycle is logically different. During flexion, muscles perform the movement against the action of gravity and primarily start is very difficult. During extension at the beginning of the movement they can use gravity to start movement easier but the second phase of movement cycle is more difficult.

During flexion both individuals reached superthreshold activation very early at the beginning of the movement cycle and necessary level of activation decreases before the end of movement cycle. During last stage of flexion gravity influences motion completion less because forearm holds a very sharp angle to the pull of gravity and also inertia helps to finish the movement, therefore level of activation was low. The ability of MS to use inertia during finishing stage of flexion and low impact of gravity together with better strength quality was probably main reason for difference between both men. Therefore differences of time of activation during flexion were mainly created by different time of termination because the start of activation was similar at the beginning of the movement cycle for both men. Shorter time of activation was assumed especially for the primary muscles in MS due to higher level of performance and better adaptation to the movement and technique, also the experience with exercise on the fitness machine should play a major role. But we found out the significant difference between men for 2 muscles only (deltoideus $\mathrm{m}$., brachioradialis $\mathrm{m}$., longer in MN). The results for biceps $m$. were similar or identical. Activation of trapezius $m$. was shorter in MN. This result for biceps $\mathrm{m}$. or trapezius $\mathrm{m}$. we did not expect, rather shorter time of activation in MS of all muscles. It could also be the consequence of different speed of motion each men.

We did not find out common tendency of activation (extending or shortening time) for the whole time of activation for all muscles during increasing load. Tendencies in the time of activation during increasing load were specific for each muscle. During flexion we found out for about half of results the tendencies to extend time of activation with increasing load but for second half the results were found out consistent, very similar or the changes were irregular. Tendency to extend time of activation was found for 2 principal muscles in MN (brachioradialis $\mathrm{m}$., biceps $\mathrm{m}$.) and in MS for 1 main and 1 secondary muscle only (biceps $\mathrm{m}$., deltoideus $\mathrm{m}$.).

During extension, it is possible to observe certain tendencies towards the change in the strategy of activation in individual participants. Except for the biceps $\mathrm{m}$., activation in MS was started significantly later for all remaining muscles and the basic differences between research participants for the overall time of activation were caused by different time of beginning of activation. Termination did not show any significant differences in the secondary and the primary muscles. At the beginning of extension the gravity can help to start movement without superthreshold activation but during second stage muscles have to brake the arms movement to the end of movement cycle and the activation has to increase. In $\mathrm{MN}$ activation reached 
superthreshold level very fast at the beginning of the movement cycle and the activation_dropped under threshold level at the end of movement cycle. In MN superthreshold activation was found out by even a very sharp angle in the elbow joint at the beginning of movement cycle (excerption biceps $\mathrm{m}$.). In MN, superthreshold activation was found out for nearly whole movement cycle, he was not able to efficiently make use of gravity acting at the beginning of the movement cycle and muscle activation started very early. In MS, superthreshold level of muscle activation is reached at greater angle in the elbow joint, during later part of movement cycle and it was maintained to the end of the movement cycle. Slight load in MS corresponds to shorter time as well as later beginning of activation. Also from the point of view of the movement technique and experience, a sportsman was able to use of gravity acting at the beginning of movement during extension which helps to start the movement without higher effort and superthreshold activation and braking muscle activity starts with delay. Overall time of activation was especially in MS of all muscles shifted to the later phase of the movement cycle. The tendencies during extension in the time of activation at increasing load were specific for each muscle. The most commonly tendency was found in prolonging the time of activation for deltoideus m., brachioradialis m. in MN, and trapezius,m., brachioradialis, m., biceps,m. in MS.

\section{CONCLUSIONS}

We found out differences and also very similar timing of both research participants for observed muscles.

Unexpected result was similar muscle activation m. biceps brachii of both men.

Differences in the activation time in flexion were caused especially by a different finishing time.

Differences in extension were caused mainly by the later start of the activation in MS.

We found out some interesting results, but for more relevant results which could better explain the difference of muscle activation between well trained and untrained population are needed and a follow-up survey are necessary.

The paper is the result of research project: "Institutional developing project" (RP 90518010) of Brno University of Technology. The project was financed by Brno University of Technology.

\section{REFERENCES}

1. Antonopoulos, C., Patikas, D., Koutlianos, N., Papadopoulou, S.D., Chatzopoulos, D., Hatzikotoulas, K., Bassa, E., \& Kotzamanidis, Ch. (2014). The Effect of Fatigue on Electromyographic Characteristics during Obstacle Crossing of Different Heights in Young Adults, Journal of Sports Science and Medicine, 13, 724-730.

2. Benedetti M. (2001). Muscle activation intervals and EMG envelope in clinical gait analysis. IEEE Engineering in Medicine and Biology Magazine, 20(6), 33-4.

3. Berg, H.E., Larsson, L. \& Tesch, P.A. (1997). Lower limb skeletal muscle function after 6 wk of bed rest. J Appl Physiol. 82(1), 182-8.

4. Bilodeau, M., Schindler-Ivens. S., Williams, D.M., Chandran, R., \& Sharma, S.S. (2003). EMG frequency content changes with increasing force and during fatigue in the quadriceps femoris muscle of men and women. Journal of Electromyography and Kinesiology, 13(1), 83-92. 
5. Bosch, P. R., Snyder, A. R., Scherr, T. M., \& Stupczy, M. (2011). Differences in Shoulder Muscle Activation Patterns During Proprioceptive Neuromuscular Facilitation Using Manual and Elastic Band Resistance, Athletic Training \& Sports Health Care, 3(2), 69-75.

6. Chimera, N.J., Swanik, K.A., Buz Swanik, C., \& Straub, S.J. (2004). Effects of Plyometric Training on Muscle-Activation Strategies and Performance in Female Athletes. Journal of Athletic Training. 39 (1), 24-31.

7. Dasteridis, G., Pilianidis, T., Mantzouranis, N., \& Aggelousis, N. (2012). The Effect of Athletics Training on Isometric Strength and EMG Activity. Biology of Exercise, 8(1), 37-46.

8. De Luca, C.J.D. (1997). The use of surface electromyography in biomechanics. J. Appl. Biomech., 13(2), 135-163.

9. Edgerton, V.R., \& Roy, R.R. (1994). Neuromuscular adaptation to actual and simulated weightlessness. In: Bonting SL (Ed.), Advances in space biology and medicine, vol. 4. Greenwich, CT: JAI Press, 33-67.

10. Flanders, M. (1991). Temporal patterns of muscle activation for arm movements in three-dimensional space. J. Neurosci., 11(9), 2680-2693.

11. Huges, C.H. J., \& McBride, A. (2005). The Use of Surface Electromyography to Determine Muscle Activation during Isotonic and Elastic Resistance Exercises for Shoulder Rehabilitation, retrieved from http://www.thera-bandacademy.com/elements/Clients/docs/Hughes2005shemg_071905_101749.pdf.

12. Hug, F. (2011). Can muscle coordination be precisely studied by surface electromyography? Journal of Electromyography and Kinesiology, 10(21), 1-12.

13. Jongen, H.A.H., Denier van der Gon, J.J., \& Gielen, C.A.M. (1989). Activation of human arm muscles during flexion/extension and supination/pronation tasks: a theory on muscle coordination. Biol. Cybern., 61, 1-9.

14. Kellis, E., \& Baltzopoulos, V. (1998). Muscle activation differences between eccentric and concentric isokinetic exercises. Med.sci spot exer. 30(11), 1616-23.

15. Konrad, P. (2005). The ABC of EMG: A Practical Introduction to Kinesiological Electromyography, retrieved from http://www.noraxon.com/docs/education/abc-of-emg.pdf.

16. Madeleine, P., Bajaj, P., Søgaard. K., \& Arendt-Nielsen. L. (2001). Mechanomyography and electromyography force relationships during concentric, isometric and eccentric contractions. Journal of Electromyography and Kinesiology, 11(2), 113-21.

17. McCurdy, K., O'Kelley, E., Kutz, M., Langford, G., Ernet, J., \& Torres, M. (2010). Comparison of Lower Extremity EMG Between the 2-Leg Squat and Modified Single-Leg Squat in Female Athletes. Journal of Sport Rehabilitation, 19, 57-70.

18. Merletti, R., Knaflitz, M., \& De Luca, C.J. (1990). Myoelectric manifestations of fatigue in voluntary and electrically elicited contractions. Journal of Applied Physiology, 69(5), 1810-1820.

19. Merletti, R., \& Bonalo, P. (2008). Surface Electromyography (EMG) Wiley Encyclopedia of Biomedical Engineering. John Wiley and Sons, Inc.

20. Nizam, U.A., Sundaraj, K., Ahmad, B.R., Rahman, A., Ali, A., \& Islam, A. (2012). Electromyographic Responses during Elbow Movement at Two Angles with Voluntary Contraction: Influences of Muscle Activity on Upper Arm Biceps Brachii. Research Journal of Applied Sciences, Engineering and Technology, 4(22), 4591-4595.

21. Rainoldi, A., Melchiorri, G., \& Caruso, I. (2004). A method for positioning electrodes during surface EMG recordings in lower limb muscles. Journal of Neuroscience Methods, 134, 37-43.

22. Rodová, D., Mayer, M., \& Janura, M. (2001). Současné možnosti využití povrchové elektromyografie, Rehabilitace a fyzikální lékařství., 8(4), 173-177. 
23. Sale, D., MacDougall, J., \& McComas, A. (1983). Effect of strength training upon motoneuron excitability in man. Medicine Science and Sport Exercise, 15, 57-62.

24. Sergio, L.E., \& Ostry, D.J. (1995) Coordination of multiple muscles in two degree of freedom elbow movements Exp. Brain. Res., 105, 123-137.

25. Solomonow, M., Baten, C., Smit, J., Baratta, R., Hermens, H., D’Ambrosia, R., \& Shoji, H. (1990). Electromyogram power spectra frequencies associated with motor unit recruitment strategies. $\mathrm{J}$. Appl. Physiol. 68, 1177-1185.

26. Sutherland D. (2001). The evolution of clinical gait analysis. Part 1. Kinesiological EMG. Gait Posture, 14(1), 61-70.

27. Špulák, D. Čmejla, R., Bačáková, R., Kračmar, B., Satrapová, L., \& Novotný, P. (2012). Muscle Onset Detection in Electromyograms: Effects of Averaging after Segmentation. In. Biosignal 2012: 21st Biennial International Conference. Brno.

28. Ting, L.H., \& McKay, J.L. (2007). Neuromechanics of muscle synergies for posture and movement. Curr Opin Neurobiol., 17, 622-628.

29. Turpin, N.A., Gue'vel, A., Durand, S., \& Hug, F. (2011). Effect of power output on muscle coordination during rowing. Eur. J. Appl. Physiol., 111(12), 3017-29.

30. Yamaguchi, K., Riew, D.K., Galatz, L.M., Syme, J.A., \& Neviaser, R.J. (1997). Biceps activity during shoulder motion: An electromyographic analysis. Clin. Orthop. Relat. R., 336, 122-129. 